\author{
И. Б. Левонтина \\ Институт русского языка им. В. В. Виноградова РАН \\ (Москва, Россия) \\ irina.levontina@mail.ru

\section{ОБ ЭКСПАНСИИ ВИНИТЕЛЬНОГО ПАДЕЖА В КОЛИЧЕСТВЕННЫХ ОБОРОТАХ*}

В статье исследуется неканоническое употребление ВИН количественных контекстах, где в норме используются другие падежные формы с предлогами и без них. Такое употребление присуще, особенно в разговорной речи, довольно широкому кругу существительных с количественным значением: тысяча и тыщқа (тыщиока), сотня, соточка, сотка, дюжина, пара и парочка, уйма, прорва, тьма, половина, тонна, минута (речь идет о существительных склонения на - $a$, потому что именно у них не совпадают формы ИМ и ВИН). Ср. У меня кучу дел; Ecть минутку?; Есть еще парочку подтипов; Было уйму впечатлений; Купила билеты по тышу; Было половину десятого; Сказать по пару слов. Делается попытка обнаружить механизм, объясняющий поведение ВИН во всех подобных случаях.

Мы предполагаем, что пониженная семантическая нагруженность падежных противопоставлений у количественных слов приводит к редукции этих противопоставлений до оппозиции прямые падежи - косвенные падежи, а затем и только до прямых падежей, которые у большинства числительных не различаются. Когда же используются количественные существительные, в парадигме которых ИМ и ВИН различается, между этими формами происходит конкуренция, в которой нередко выигрывает ВИН как более естественный для слов, типичных для неагентивных употреблений.

Как кажется, можно наблюдать усиление этой тенденции в последнее время, однако это трудно достоверно установить. Сама тенденция не новая, а возможно, стоит говорить о том, что у количественных слов система падежных противопоставлений так до конца и не сформировалась.

Ключевые слова: русские количественные конструкции, падежные противопоставления, разговорная речь.

* Исследование поддержано РФФИ, грант 19-012-00291А, «Подготовка четвертого выпуска Активного словаря русского языка». 
Многие обращают внимание на нередко встречающееся странное использование винительного падежа в контекстах типа: У меня кучу дел; Ecmь минутку?; Есть ещзе парочку подтипов; Было уйму впечатлений; Купила билеты по тышу; Было половину десятого; Сказать по пару слов. Это явление было отмечено в небольшой работе М.А. Холодиловой и А.Б. Летучего «Было пару человек: об одной количественной конструкции в русском языке» (Тезисы конференции 2011 г.). В ней сказано, что квантификаторы napa, куча, масса могут использоваться в ВИН в естественных контекстах номинатива и что в интернете есть и примеры, в которых «форма аккузатива заменяет, например, датив или генитив при предлогах». Многие из таких примеров выглядят совершенно ненормативными, однако есть и вполне естественные, пусть и не канонические:

Прошло пару месяцев <тысячу лет>;

В тысячу триста восьмидесятом году;

Ср. также следующий пример из записи, автор которой, Лев Рубинштейн, бесспорно, замечательный стилист:

Удивить никто не удивил, но пару имен, скажем так, огорчили (ответ на вопрос Вас кто-то удивил? о списке подписавших некое письмо).

А употребление ВИН mысячу вместо ИМ в составе составных числительных не только давно и часто встречается, но и специально отмечается как ошибочное:

— Я, браток, в тысячу девятьсот пятом годе на усмирении был. [М. А. Шолохов. Тихий Дон. Книга первая (1928-1940)]

Выберите нужную форму числительного:

1) (В тысячу девятьсот тридцать девятом - в тысяча девятьсот тридцать девятом) году началась Вторая мировая война. https://znanija. com/task/2071 853

6 февр. 2012 г. - грамматическая ошибка допущчена в предложении: - название химических элементов, открытых до тысячу восьмисотого года... https://otvet.mail. ru > Домашние задания Ответы@Mail.Ru: помогите по русскому!!!!

Оказывается, что неканоническое употребление ВИН присуще довольно широкому кругу существительных с количественным значением: тысяча и тыщи (mblщзонка), сотня, соточка, сотка, дюжина, пара и парочка, уйма, прорва, тьма, половина, тонна, минута (речь идет о существительных склонения на - $a$, потому что именно у них не совпадают формы ИМ и ВИН), - и круг контекстов ВИН тоже намного больше (и другие падежи, в том числе и без предлогов):

В качестве пару слов хотелось бы вам сказать...;

Машина была найдена в пару кварталов от дома; 
Отдам лекарства. Почти все нетронутые. В пару пачек не хватает по 1-2 таблетки;

плиз подскажсте игру < ... чттобы пару людьми управлять)) спасибо вам; Мне кажется я вернулась с пару килограммами, потому что это выпечку, хлеб, булочки, просто не возможно не попробовать;

будешь общаться с тысячу людьми это не значит, что в твоем сердце не будет пустоты;

А для некоторых нормальная жизнь - это жизнь с кучу друзей, не работая вообще.

И я не удержусь от сегодняшнего заката: буквально пару мгновений вспыхнуло, осветило, поразило... Никаких фильтров. здесь: Сокол (район Москвы)

https://www.facebook.com/photo.php?fbid=10213521832351 743\&set=gm.256 6627676704 626\&type $=3 \&$ theater

При рассмотрении примеров по отдельности нередко возникает соблазн предложить какие-то «локальные» объяснения появления ВИН: смешение разных конструкций, анаколуф и т. д. Ср. приведенный выше пример:

Машина была найдена в пару кварталов от дома.

Здесь можно было бы сказать, что произошло смешение двух конструкций: в паре кварталов и за пару кварталов. Такое объяснение, однако, было бы невозможным для следующего примера:

В пару пачек не хватает по 1-2 таблетки.

Фразы типа Пришло пару человек, Было кучу гостей можно было бы пытаться связать с тем, что говорящий начинает фразу с глагола в форме среднего рода, как это естественно при подлежащем - сочетании с числительным (Было пять человек), а существительное женского рода плохо монтируется с глаголом в форме среднего, поэтому говорящий как-то уходит от необходимости сочетать глагол с существительным по роду, отказавшись от ИМ. Однако это не объясняет, почему выбирается именно ВИН. Кроме того, форма среднего рода глагола все-таки встречается в сочетании с существительными женского рода:

Каждый год, перед Новым Годом, я мечтаю, чтобы у меня было паратройка спокойных, свободных от работы дней.

https://www.pinterest.ru/pin/685180530781703 635/

Там было парочка вариантов.

https://rutube.ru/video/ae319ca5c27f67f647c4ea63dd6b7c5a/

Наконец, такое объяснение не работает для предложений с глаголом в форме настоящего времени или нулевой связкой; ср. У меня по дороге кучу магазинов. Сочетание есть парочку, которое никак невозможно объяснить трудностями согласования по роду, например, - совсем не редкость: 
Мне 21 год. У меня светлые кучерявые волосы, болотные глаза. Я считаю себя интровертом, но у меня есть парочку друзей из универа. https://ficbook. net/readfic/6572307

Есть парочку вопросов.. Всем здравствуйте, вчера встретилась с двумя вопросами health-diet.ru> $255822 / \mathrm{blog} / 151575$

Движемся дальше.., есть парочку новых идей, которые хочется протестить в этом году instagram.com $>$ p/BtFGKGTnKKu/?hl=bn

Eсть парочку способов, но они легальные, поэтому даже не надейтесь, что здесь вам попадётся статья, для получения чего-либо обманным путем...хотя, мы ещуе посмотрим. сотрuterinfo.ru〉Лайфхак на 6 способов

есть парочку минусов, но они минимальны,в цчелом хорошее средство. ... эфффект есть). irecommend.ru〉content/est-parochku-minusov-no-oni...

Показателен следующий пример, где говорящий использует конструкцию с ВИН, а собеседник его поправляет:

Ответы Mail.Ru: Всем привет! У меня есть парочку вопросов, может кого заинтересует, присоединяйтесь... «Есть парочку» - звучит как-то не порусски. Падежи прогулял в школе? Надо было сказать «есть парочкА вопросов» :-) otvet.mail.ru〉question/191798561

Конечно, в таких случаях можно говорить о влиянии посессивной конструкции с глаголом иметь. И скорее всего, частные объяснения, подобные приведенным выше, имеют право на существование, однако лишь как указание на дополнительные факторы, а должен быть какой-то общий механизм, объясняющий поведение ВИН во всех подобных случаях.

При этом кажется довольно удивительным, что так активизируется здесь именно ВИН. Гораздо естественнее было бы ожидать активизации РОД: у него есть и какие-то количественные ассоциации (добавить соли), и возможность сочетания со связкой во фразах типа Их там не было, а в просторечии и без отрицания: Их сть у меня.

Чем же объясняется экспансия не РОД, а ВИН, на первый взгляд непонятно.

Впрочем, отдельно стоит сказать о предлоге по в распределительном значении. В описании предлога по Л. Иомдин в [Иомдин 1991] выделяет специальное распределительное ПОІV с ДАТ, ВИН и РОД (по сотне, по сто, по пятидесяти) и описывает правила выбора падежа (с. 118-119). Заметим, что три варианта падежа при предлоге в однотипном контексте - это для русского языка некоторая редкость.

Существительные в норме выступают здесь в ДАТ: По рублю, по гривеннику, по доллару, по полтиннику — по десять, по сто. По тыщу, по пару слов при всей странности этих сочетаний как раз конструктивно проще всего - здесь можно усмотреть выравнивание по числительным. Если бы дело было только в распределительной конструкции, можно было бы ограничиться констатацией изменения предложного управления. 
Разнобой в выборе падежной форме в распределительной конструкции с предлогом по - явление далеко не новое; ср.:

Да чтобы не запрашивать с вас лишнего, по сту рублей за штуку! - сказал Собакевич. - По сту! - вскричал Чичиков, разинув рот... (Николай Гоголь, Мертвые души)

... нынбшнему окладу жалованіемъ, при рисовальномъ-мастеръ одинъ по сту по сороку рублей, подмастерье одинъ по сту рублей, учениковъ четверо, ...

https://books.google.ru/books?isbn=5458157486

За выводимых из своей вотчины «девок» княгиня приказывала присылать по ста рублей с каждой. За всякую провинность предписывались ею строгие ...

Е.Р. Дашкова. Ее жизнь и общественная деятельность В.В. Огарков 2018 - Biography \& Autobiography https://books.google.ru/books?id=WtNDwAAQBAJ

... чтобы нбкоторое число торгующихъ казаковъ было освобождаемо отъ служббы, со взносомъ отъ каждаго изъ нихъ въ войсковой доходъ по ста рублей. В. Д. Сухоруков - $2013-$

Historyhttps://books.google.ru/books?isbn=5458090 462

В Перми за шесть взяток по сто рублей уволили женщину-полицейского. https://progorod59.ru/news/26601

Туристы скинутся по сто рублей за Крым - Рамблер/новости

https://news.rambler.ru/articles/36816 690-turisty-skinutsya-po-sto-rubley-zakrym/

На эту тему есть корпусное исследование [Гришина 2011].

Прежде чем высказать гипотезу о механизме экспансии ВИН, приведем материал, в основном извлеченный из блогов, демонстрирующий, что описываемые неканонические употребления ВИН достаточно распространены. Материал рассортирован по группам количественных слов и проводится с сохранением орфографии и пунктуации источника.

\section{Тысяча, дюжина, сотня, половина}

И прочло сотню лет, вспоминаю о всём

Что так было давно и прошло одним днём. https://steamcommunity.com/id/ DooM_Archi

- Оленька, боже ты мой, когда это было! Прошло тысячу лет, после нашего расставания я очень переменился. [Евгений Сухов. Делу конец - сроку начало (2007)] 
Пьют кровушку народную, а сами воруют сволочи, пенсия вот у меня тышу рублев, а как, скажите, люди добрые, на такие деньги жить-то? https:// books.google.ru/books?isbn=5457279367

ахаха, у меня тышу таких фото) муж их называет ласково - кораллы . - какие ножки смешные. пальчики так торчат смешно. https://www. babyblog.ru/.../56a66992843983ae168b456a-nu-hot-chem-to-syn-pohoz...

Ответы@Mail.Ru: Чёт так жить хотца до тыщу лет! К чему бы такая нездоровая фигня? otvet.mail.ru>question/35318726

Кстати имеются Рупь с Николашкой, Яндекс грит по состоянию может стоить до тыму баксов forum.ykt.ru>viewmsg.jsp?id=21182 862

Ответы@Mail.Ru: что пожелать брату? что пожелать брату на день ...

- Скажи ему душевно так- братишка живи до тышу лет... Потом умри! Бесогон https://otvet.mail.ru

до тышу лайков ещзе долгооо:

https:/www.e1.ru/talk/forum/read.php?f=67\&i=13416600\&t=134166001 июн. 20182.

- ... более 50 километров только за счет электричества и при этом будут весьма динамичными - разгон до сотню займет около 4 секунд evmode. $\mathrm{ru} / 2018 / 06 / 01 /$ alfa-romeo-vyipustit-srednemotornyiy-supergibrid-8c/

Тренируйся, пиши какие-нибудь черкушечки, никому их не показывай, пиши, переписывай по дюжину раз, только тренируйся. вроде бы все есть, но в ... https://pikabu.ru/.../zaranee_proshu_proshcheniya_za_oshibki_sintaksicheskie_ punktuat...

каждый год этих автобусов списывали по дюжину. dnevniki.ykt.ru/ Grenadier_Thomas/1091508?promo_inner\&mobile=true

... бывшим чемпионом. И тот и другой имеют по дюжнну побед за плечами, и лишь один прочгрыш, который получили в битве друг против друга... https://www.ivi.ru > Фильм > Комедии > Забойный реванш

Если бы я мог знать, что я попытаюсь успокоиться, я получу разум, чтобы быть уверенным, что у меня есть половину ума. https://textypesen.com/thelemonheads/rest-assured/

В восторженных тонах оченил прошедший чемпионат и Владимир Морозов: «Очень удачный чемпионат Европь для нас, самый лучший в нашей российской истории. Учитывая, что у нас многих не было - Юлии Ефимовой, ребят, которые уехали на чемпионат мира среди военнослужаших, и то, что было половину больных, выступили мы очень даже неплохо». https://www.mos.ru/news/item/34262 073/ 
в то время, когда на наружных часах, над подъездом, было половину 10-го, часы в вестибюле показывали - четверть 12-го, в зале первого класса одиннадиать!.. [неизвестный. Слухи и факты (1912.12.11) // «Одесский листок», 1912]

Уже не первый раз сталкиваюсь с ситуаџиями где обычно нужно повторять какой либо фон до половину а на вторую другой. toster.ru>q/169957 13 comments on " В общем с передними стеклами какая та фигня когда поднимаю до половину”. ffocus-help.ru〉...obshhem...perednimi...ta...dopolovinu/

1 сентября импорт газа на Украину по реверсу из Словакии сократился почти до половину от максимальной мощности --- сообщает РИА Новости aif.ru〉money/market/kiev_snizil_pochti_do...revers...

Нажмите до половины кнопку спуска затвора, чтобы загорелась метка ... В нормальном режиме при нажатии кнопки спуска затвора до половину фиксируются $A F$ (автофокус) и $A E$ (автоматическая экспозииия), photomanual.ru>download/olympus/manuals/olympus_e...

... заранее выписать пропуск на определенный час, когда еще работает бюро пропусков-до половину пятого. https://adiaphora22.livejournal.com/196234. html

26 апр. 2011 г. - ... по УБ не выглядит недостижимой. Индекс ПФТС до половину пятого, скорее всего останется между отметками в 1040 и 1060 пунктов. www.ux.ua/ua/m/12/1836/20110426-utrenniy-obzor-26-aprelya-vsesamoe.aspx

... а нижний - Христорождественский. Работает только верхний храм, но и то, до половинупятого (до 16.30). https://otzovik.com/review_6430003 html

21 мая 2012 г. - ... кто обычно спокойно относится к спортивным баталиям, сегодня в Хабаровске с половину пятого утра не сомкнули глаз, наблюдая за ... khab-vesti.ru > Новости

30 дек. 2013 г. Люди которые стояли с половину пятого утра, попали в храм к половине десятого , вечера. www.logoslovo.ru/forum/all_362/ topic_8479_9_0_0/

\section{Пара, парочка}

Прошло пару лет, разочарование от МКЦ прочло, и где-то я вычитала про чай для похудения «Летящая ласточка». [Красота, здоровье, отдых: Красота (форум) (2005)]

Прошло пару месячев, он был арестован вторично и расстрелян. [Анна Бергер. Annenschule (2003) // «Вестник США», 2003.12.24] 
- прошло пару месячев, и все как будто подернулось ряской. [Антон Петров. Дочь, ложь и видео (2003) // «Вслух о...», 2003.07.01]

Прошло пару месяиев, пока я привык к мысли, что теперь они приходят нас не вязать, а охранять. [Андрей Макаревич. Все очень просто (1990)]

Было пару маргиналов, которые» общались «с духами, а потом духи пускались в бега, не боясь, что им влепят за дезертирство. [коллективный. Форум: Дедовщина и неуставные отношения. Кто есть кто в современной армии (2011-2013)]

Дружба,что это вообще такое? Да ты думаешь,у тебя есть парочку друзей,которые с тобой будут до конца,он же с детства,либо знакомы пару лет и... https://vk.com/lotov3

\section{Минута (секунда), тонна}

И мы можем пойти, как вы хотите пойти. Теперь у меня есть минуту. slushat-tekst-pesni.ru/jagged-edge/what-you-tryin-to-do

На всё про всё у тебя есть минуту https://vk.com/gogunskaya_milana_star

15 июн. 2015 г. - Сыграем в игру, Джерри Ли. У тебя есть минуту, чтобы отыскать своего милого бакугана. Не успеешь - последствия будут плачевными. https://ficbook.net/readfic/2742 946/8666011

Правда машину я не взял, поскольку косяков там было тонну, но именно с того дня я понял, что хочу именно чепырку https:/www.drive2. $\mathrm{ru} / \mathrm{l} / 465402932146209275 /$

Просто хотелось узнать, как тормозилки показывают себя. +1. 4 года . somebody. Ну блин, нельзя сравнивать. У меня тонну семсот, а у тебя 900 https://www.drive2.ru/c/1839849/

У меня тонну техники от сяоми, от телефона, до камеры. Я очень люблю эту фирму https://technopoint.ru/product/7eb34a18621d3330/provodnaa... xiaomi.../opinion/

y меня тонну дел... https://www.wattpad.com/579536445-чанс-любовь-между-монстром-и-человеком-......

Люди, которые говорят, «Там было тонну людей» на мероприятии, если буквально означает только около 15 человек. https://allwomenstalk.com/ $\mathrm{ru} / 5689596 \mathrm{~d} 0 \mathrm{c} 4 \mathrm{fe} 7 \mathrm{e} 8488 \mathrm{~b} 47 \mathrm{cc}$

... поэтому...в понедельник мы были на диком пляэу, который оказывается не был диким, потому что там было тонну людей, как и на всех пляжах www.pictaram.org/hashtag/джуниорклуб 
Надо, впрочем, отметить, что слово тонна употребляется здесь в либо в значении 'тысяча' (тонна семьсот об объеме двигателя), то есть примыкает к первой группе, либо в значении 'очень много', то есть примыкает к следующей группе. Примеров типа Было тонну песка пока не встретилось, хотя они, скорее всего, тоже бывают.

\section{Куча, масса, тьма, уйма, прорва}

1300 руб. Здравствуйте, меня зовут Валентина. С недавних пор я пенсионер, и у меня массу свободного времени, но так как за все нужно платить, даже за это... rutwi.ru>mos/moscow/service/uborka/82/

Вот и у меня массу счастливых примеров. Но где эту достойную nару найти!!! mur-zilka. ... 23 марта 2017 в 12:19 sovet.kidstaff.com. ua>question-1781 641-1

Анекдот № 237 995. Меня не беспокочт то, что у меня кучу минусов... меня беспокоит отсуствие плюсов. vk.com>topic-46515657_27406964

У меня кучу вопросов!!! Но буду по одному кидать ) BabyBlog.ru>momlife/ ru/post/...-u-menya-kuchu...no-bud forum.ykt.ru>viewtopic.jsp?id=1337 117

Ответ на тему: Уменя кучу вопросов появилось после прочтения «отчеты о родах».

Помогите, у меня кучу проблем otvet.mail.ru>question/199685964

Девочки,у меня кучу вопросов 1) Нужно открепить ребенка от поликлиники,чтоб прикрепиться к другой,по причине переезда. Нужны ли какие-нибудь документы? И может ли сделать это бабушка? mamysmolenska.ru〉devochki-u-menya-kuchu-voprosov/

(@salnikovama) on Instagram: “Весь этот год было уйму эмоций, есть хорошее и плохое. https://www.instagram.com/p/Br_OHxcFa5w/

Mы могли общается до самого вечера, ведь тёпльх воспоминаний было уйму, но, почему-то вдруг настала тишина https://books.google.ru/ books?isbn $=5041358575$

На самом деле было уйму времени чтобы вывернуть на встречную полосу, но и женщина тоже не права. Водитель если бы смотрел мог бы немного ... https://vc.ru/u/126715-lubsan-banteev

Вот и практически закончился учебный год 2016-2017... Этот год был очень тяжёлым, активным, насыщенным и ярким... Было уйму побед, травм, боли и ... https://vk.com/wall-1114 505?own=1 3 нояб. 2018 г. — ... подружились уже в Америке, съездили в такие места, как Ниагарский водопад, Чикаго и два раза в Кливленд. Впечатлений было уйму. www.workandtravel. $\mathrm{ru} /$ history-members/work-and-travel-2018-cedar-point.html 
29 сент. 2015 2. - Достался он нам с женой после космича 2141.Эмоций было прорву. Но прошло уже два года, я сменил уже две машины... https://stapico.ru/tag/янаписала https://media.auto.ru > ... > Mercedes-Benz > C-klasse > I (W202) Рестайлинг

еле-еле провели набор было очень сложно было тьму людей но мы это сделали !!! всем спасибо кто участвовал !!!15. 00-17.22. https://vk.com/ ppsnext

Подобные употребления имеет смысл рассматривать не как разрозненные конструктивные сдвиги, а как следствие того, что в количественных оборотах падежные противопоставления ослаблены (мы воспринимаем пять столов как 'столы числом 5'), так что количественные выражения могут застывать в одной падежной форме. На роль этой формы, как естественно ожидать, может претендовать и форма ИМ:

Корейская монета в половина вона (1907)

Может, в половину?

Угу, исправил

https://www.bestiary.us/images/korejskaja-moneta-v-polovina-vona-1907

В половина случаев / в половина случаях;

Почти в половина случаев больные поступали в стационар (4o,3\%) с «синдромальими» диагнозами medical-diss.com > Инфекиионные болезни

28 июн. 2011 2. - В половина случаев они даже подпись не ставят (про печать и указания своих реквизитов я вообще молчу). https://www.glavbukh. ru/forum/showthread.php/58361 10 июн. 2008 г. — в половина случаях согласен.... как говорится девушка за рулем как обезьяна с гранатой!!! https:// otvet.mail.ru > Авто, Мото

Наш тотал в домашних матчах Бетиса и в выездных матчах Реала пробивался примерно в половина случаях. https://vprognoze.ru/forecast/pro/ fcpfootball/.../6993 098-betis-foly-real-m-foly.htm

Можно привести и примеры существительных, не различающих формы ИМ и ВИН, где форма ИМ/ВИН используется на месте формы косвенного падежа:

Суть игры мы должны досчитать до миллион Так я начну! icraft. uz`topic1200.html

Продажа авто с пробегом до миллион рублей в Москве. carsguru. net〉Быстрый подбор автомобиля >ag_used_car_million

Особенно показателен следующей пример, где. впрочем, строго говоря, нельзя сказать, ИМ перед нами или ВИН (но скорее все же ИМ): 
«Время секонд-хенд» Светланы Алексиевич вошло в тройку лучших книг ХХІ века». И на сей раз попробуем не полопаться от зависти $<\ldots>$, а, досчитав до пять, выдохнуть и поздравить потрясающего литератора. https://www.facebook.com/ganna.oganesyan/posts/2243036669156855

Благоприятный контекст для этого явления создает и ситуация со склонением числительных. У большинства числительных различаются три падежных формы (пять, пяти, пятью), у сорок, девяносто и того меньше (с числительным сто сложнее, так как, кроме формы ста, есть -сот и -стами в составе сложных числительных); у полтора есть еще женская форма полторы.

При этом носители русского языка в большинстве своем очень неуверенно владеют склонением числительных - не только сложных (ср. недостижимую для большинства форму тремястами) и даже составных. Чаще всего здесь вместо нужной формы фигурирует РОД: трехстами или трехсот вместо тремястами, пяти вместо пятью и т.д.

Возвращаясь к словам на - $a$, различающим формы ИМ и ВИН, отметим, что при указании времени слово половина вообще очень часто встречается в форме ИМ с предлогом:

встретимся в половина пятого;

28 мар. 2013 г. - Я сегодня успела только к половина первого : https://www. yburlan.ru/.../obsuzhdenie-zanjatij-pervogo-urovnja-gruppy-1590-800.ht...

2 нояб. 2016 г. - Разве сейчас это проблема. Вот когда я ходил в школу в третью смену, к половина четвертого https://abonents-ntvplus.ru > Форум > Спорт > Футбол

- С удовольствием Джон. Посмотрим кто больше острижёт овеи к половина четвёртого дня. www.obshelit.com/remarks/add/11 619/

... на завтра и ложиться отдохнуть. Подъём, с учётом впереди лежавшего пути, назначен на три часа. Рассчитывали быть у чели к половина седьмого. altfishing-club.ru/articles_fishing.html/_/ohota/vesna-pod-kamnem16-god-r43

Вчера я был на известном уже многим форелевом платнике. Рыбалка можно мягко сказать не удалась! Приехал к половина второго ... https://ilixfishing.com > ... >

И только к половина пятого поняла-лялька хочет манной каши). Ну че делать-встала сварила кашу)))))))). https://www.disput.az > Форумы > Пенелопа - Women Forum > Материнство

Причем такое употребление совершенно не новое ${ }^{1}$ :

${ }^{1}$ Стоит обратить внимание и на проблему использования слов половина и четверть без предлога в обозначениях времени, которая постоянно вызывает споры среди лингвистов. Яркий пример - недавний пост лингвиста Дмитрия Сичинавы в социальной сети и дискуссия под ним: 
Две минуты после половина первого. - Пора, - сказал Пален. - Höchste Zeit, — подтвердил Беннигсен (М. Алданов)

https://books.google.ru/books?isbn=5447552540

Я хотя попадал почти ежедневно часам к половина второго, $\kappa$ двум на службу, - и успевал там поперевести из Тирсо де Молина (В. Пяст) silverage.ru/pastvstrech/

А вот застывание в форме ВИН действительно необычно и связано, видимо, с типичностью для количественных оборотов объектного и особенно обстоятельственного употребления (потратил сто рублей, провел там две недели, через десять дней, за пять лет, был там пять раз, спал два часа, шесть лет назад).

Таким образом, пониженная семантическая нагруженность падежных противопоставлений у количественных слов приводит к тенденции к редукции этих противопоставлений до оппозиции прямые падежи - косвенные падежи, с экспансией формы РОД, а затем и только до прямых падежей, которые у большинства числительных не различаются. Когда же используются количественные существительные, в парадигме которых ИМ и ВИН различается, между этими формами происходит конкуренция, в которой нередко выигрывает ВИН как более естественный для слов с типичными неагентивными употреблениями.

Как кажется, можно наблюдать усиление этой тенденции в последнее время, однако это трудно достоверно установить, так как явление это очень разговорное, а только для современного состояния мы располагаем надежным материалом (задокументированная устная речь, блоги). Ясно, однако, что сама тенденция не новая, а возможно, стоит говорить о том, что у количественных слов система падежных противопоставлений так до конца и не сформировалась.

«Четверть одиннадцатого капитан Немо стал у руля» (перевод Н. Г. Яковлевой; в других переводах предлог есть) «Котик ходит на работу половина пятого» (известная песня; вариант с номинативом запомнился мне по журналу Пионер, 1989 г.)

В корпусе с 1817, это судовой журнал Матюшкина -- у него без предлога, а у Беллинсгаузена уже с (к вопросу о Немо). Дальше есть в 1920-е и позже (Буткевич, Мариенгоф, Гуль).

Для некоторых участников обсуждения такое употребление слов четверть и особенно половина совершенно неприемлемо, для других - вполне нормально. Задается также вопрос: $A$ это точно именительный, а не accusativus temporis? Другой участник обсуждения отвечает: У Мариенгофа в «Романе без вранья» есть «Половина седьмого они обрывали звонок у тяжёлой дубовой двери с медной дощечкой, начищенной кирпичом».

Видимо, не винительный.

Это явление в обсуждении связывается с тенденцией к аналитизму вообще и с активизацией номинатива в частности, а также с типологически характерной немаркированностью локативных и темпоральных выражений (М. Хаспельмат, И. Мельчук)

https://www.facebook.com/mitrius/posts/10157474072033064

Мы здесь подробно эту конструкцию не рассматриваем, поскольку речь в настоящей работе идет о ВИН, а не ИМ. Однако нам важен этот случай как иллюстрация расшатывания падежных противопоставлений в количественных контекстах. Кстати, беспредложный ВИН, как и беспредложный РОД, издавна конкурируют с темпоральными предложно-именными конструкциями; ср. сейчас, тотчас, сию минуту, с одной стороны, и сегодня, третьего дня - с другой. 


\section{Литература}

Гришина Е.А. Дистрибутивная конструкция с предлогом по в русском языке 18 20 вв. // Лексико-грамматические инновации в современных славянских языках. Материалы 5 Международной научной конференции. Днепропетровск, 2011. С. 82-87. https://www.academia.edu/221 802/Дистрибутивная_конструкция_c_предлогом_ по_в_русском_языке_18-20_вв

Иомдин Л.Л. Словарная статья предлога ПО // Семиотика и информатика. Вып.32. М., 1991. С. 94-120.

Холодилова М.А., Летучий А.Б. Было пару человек: об одной количественной конструкции в русском языке // https://iling.spb.ru/confs/rusconstr2011/pdf/ XolodilovaLetuchiy.pdf

Haspelmath, $M$. From space to time: temporal adverbials in the world's languages [Text] / M. Haspelmath. München-Newcastle: LINCOM Europe, 1997. 181 p.

\section{Irina B. Levontina}

Vinogradov Russian Language Institute of the Russian Academy of Sciences (Moscow, Russia)

irina.levontina@mail.ru

\section{ON THE EXPANSION OF THE ACCUSATIVE IN QUANTITATIVE EXPRESSIONS}

This paper studies non-canonical use of the accusative in quantitative contexts, where other case forms with and without prepositions are normally used. Such use is characteristic of a fairly wide range of nouns with quantitative meaning: tysyacha and tyshcha (tyshchonka) 'one thousand', sotnya, sotochka, sotka 'one hundred', dyuzhina 'one dozen', para and parochka 'couple', uyma, prorva, t'ma 'a lot', polovina 'half', tonna 'ton', and minuta 'minute' (we mention $a$-declination nouns owing to the fact that their nominative and accusative forms do not coincide). An example is the sentence «Priyekhalo paru chelovek» 'A couple (acc.) of people arrived'. We hope to reveal a mechanism explaining the behavior of the accusative in all such cases. We assume that poor semantic loading of case oppositions in quantitative expressions leads to the reduction of this oppositions to two or three cases. The accusative competes with the genitive and nominative. As far as quantitative contexts are concerned, the accusative wins more often than not, because it is typical of non-agentive uses. It seems that one can observe an intensification of this trend; however, it is difficult to firmly establish whether this is the case, since this phenomenon is very conversational and we have reliable material only for the current state (documented oral speech, blogs). It is clear, however, that the tendency itself is not new, yet one might say that the system of case oppositions for quantitative words has never fully developed.

Keywords: Russian quantitative construction, case oppositions, colloquial speech. 


\section{References}

Grishina E. A. [Distributive construction with the preposition on in the Russian language of the 18-20th centuries]. Leksiko-grammaticheskiye innovatsii $v$ sovremennykh slavyanskikh yazykakh. Materialy 5 Mezhdunarodnoy nauchnoy konferentsii. Dnepropetrovsk, 2011, pp. 82-87. (in Russ.) https://www.academia.edu/221 802/Distributivnaya_konstruktsiya_s_predlogom_po_v_russkom_yazyke_18-20_vv

Iomdin L.L. [Lexical entry of the preposition po] // Semiotika i informatika, vyp.32, Moscow, 1991, pp. 94-120. (in Russ.)

Kholodilova M. A., Letuchiy A. B. [Bylo paru chelovek: on one quantitative construction in Russian] // https://iling.spb.ru/confs/rusconstr2011/pdf/XolodilovaLetuchiy.pdf (in Russ.)

Haspelmath M. From space to time: temporal adverbials in the world's languages [Text]. München-Newcastle: LINCOM Europe, 1997. 181 p. 